\title{
Analysis of role of erosion process of coal particles in generation of loss of incomplete combustion in fluidized bed boilers
}

\author{
Piotr Pelka, ${ }^{1, *}$ \\ ${ }^{1}$ Czestochowa University of Technology, Institute of Thermal Machinery, Armii Krajowej 21, Silesia 42-201 Czestochowa, Poland
}

\begin{abstract}
In the herein paper the results of research carried out in the Institute of Thermal Machinery of Technical University of Czestochowa have been presented. They concern the process of combustion of coal particles in a fluidized bed combustor. The tests were carried out on a test stand which allows modelling of conditions around the fuel particle in a real object. On the basis of the registered mass loss of the particles of Polish hard and brown coal chosen, the impact of the mass flow rate of inert material with different particle size distribution and different collision velocity with burning coal particle on the rate and level of its burning out was evaluated. The obtained results enables the estimation of the influence of both parameters on the intensity of erosion and determination of its role in the generation of fine particles elutriated out of the combustion chamber. The results also facilitated the verification of the methodology [1] of calculation described in literature relating to the total mass loss of coal particles as a result of combustion and erosion. According to this methodology, the slip velocity between the char particle and the fine bed solid is the main parameter of the erosion process alongside the attrition rate constant $k a$.
\end{abstract}

\section{Introduction}

The loss of incomplete combustion depends on many factors. Alongside the coal type and the associated physical and chemical properties, both the construction type and operating factors of the fluidization process also have an impact on its level. This loss is divided into losses related with the presence of combustible gasses hydrocarbons and carbon monoxide in gaseous combustion products caused by unburned solid carbon in the ash. The unburned carbon loss $U_{c l}$ can be calculated as follows [2]:

$$
U_{c l}=\frac{X_{c} \cdot W_{a} \cdot 32790 \cdot 100}{H H V}
$$

where $X_{c}$ is the fractional carbon in the solid waste, $W_{a}$ is the ash per unit mass of the fuel feed and $H H V$ is the heating value of coal. This loss has essential contribution to the heat balance especially in CFB boilers. Table 1 compares heat losses in conventional pulverized coal-fired boilers (PC) and CFB boilers [1]. It can be easily seen that the unburned carbon loss has a significant role in the heat balance, especially in the case of CFB boilers which can reach $2 \%$. It should be emphasized that in this comparison, data from the CFB boilers of an uncooled hot cyclone was used. New generation objects with cooled separators have lower flue gas loss, therefore the percentage share of unburned carbon will be even higher in the total heat balance. Many factors influence the unburned carbon loss and consequently the amount of carbon in the flue ash in CFB boilers, of which the following are first and foremost distinguished: coal type, particle size distribution of coal, temperature in the bulk of particle, oxygen concentration, furnace design, type of fluidization.

Table 1. Comparison of heat losses in typical PC and CFB boilers [2].

\begin{tabular}{|l|l|l|}
\hline \multicolumn{1}{|c|}{ Items } & PC (\%) & CFB (\%) \\
\hline Moisture in limestone & - & $0.06-0.10$ \\
\hline Calcination & - & 1.69 \\
\hline Unburned carbon & $\mathbf{0 . 2 5}$ & $\mathbf{0 . 5 0 - 2 . 0 0}$ \\
\hline Heat in dry flue gas & 5.28 & $5.57-5.60$ \\
\hline Moisture in fuel & 1.03 & 1.03 \\
\hline Moisture from $\mathrm{H}_{2}$ burning & 4.16 & 4.19 \\
\hline Radiation and convection & 0.03 & $0.30-0.80$ \\
\hline Moisture in air & 0.13 & 0.14 \\
\hline Sensible heat in boiler ash & 0.03 & $0.09-0.76$ \\
\hline Bottom ash & 0.05 & - \\
\hline Total loss & 10.96 & $12.9-16.31$ \\
\hline
\end{tabular}

The basic condition of the complete burning out of solid fuel is that the residence time of char particle $\tau_{p}$ must be only a little longer than the burnout time $\tau_{s}$. Both of these time periods depend on the magnitude of the afore-mentioned parameters which hinders the precise determination of their values, particularly the fact that

\footnotetext{
* Corresponding author: pelka@imc.pcz.czest.pl
} 
some of the afore-mentioned parameters undergo change together with the furnace height, i.e.: temperature, oxygen concentration, hydrodynamic conditions. The next parameter which complicates the analysis of the process is the comminution of coal particles which begins from the fuel feeding moment and lasts continuously to the moment of the elutriation of the particles from the furnace. These processes are fragmentation and erosion. On the one hand, the comminution improves the combustion conditions as a result of the increase of surface reaction of char particles as well as the continuous removal of the ash layer formed on the surface blocking the diffusion process. On the other hand, in the opinion of many authors $[3,4]$, the erosion process as a result of collision between solid material and coal particles generates fine particles of less than $100 \mu \mathrm{m}$. The residence time of coal particles above this diameter is enough to complete the burning out of fuel particles but smaller particles have significantly reduced residence time in the combustion chamber [5]. Taking into account that the process runs in the whole volume of a furnace, in subject-related literature many opinions that the erosion process, also called attrition, is mainly responsible for generating the loss of incomplete combustion and consequently the increase of the unburned carbon in fly ash can be found $[2,3,4,5]$.

\section{Effect of erosion in char combustion model}

The most popular way of determining the burning rate of coal particles in the phase of char combustion is the Levenspiel model [6], namely the shrinking unreacted core model. In CFB this model is particularly useful for the sake of high gas-solid relative velocity and abrading the ash layer on the char. The burning rate for the shrinking unreacted core model is given as follows [7]:

$$
q=\frac{c_{g}}{1 / h_{m}+1 / k_{c}}
$$

where: $\quad h_{m}=\frac{12 \phi S h D_{g}}{d_{c} R T_{m}}$

and:

$$
k_{c}=k_{o} \exp \left(-E / R T_{s}\right)
$$

Additionally, with the aim of indicating the equation (2) the erosion mass loss of char particle burning in CFB boiler $[8,9]$, the proposed new formula (5) is added.

$$
\frac{d W_{c}}{d t}=q A+\frac{k_{a} U_{g} W_{c}}{d_{a v}}
$$

According to this formula the intensity of mechanical mass loss depends on the external surface area of char particle exposed to erosion $W_{c} / d_{a v}$, superficial gas velocity $U_{g}$ and attrition rate constant $k_{a}$. The range of the rate constant in combustion assisted attrition in a fast bed is within the range of $0.5 \times 10^{-7}$ to $5 \times 10^{-7} \mathrm{~kg} / \mathrm{s}$
[3]. Its value may only be estimated during the experiment. In the case of conditions in CFB, the hydrodynamic force is proportional to the slip velocity between the char and the abrading bed material [9] $U_{g}=\left(U_{c}-G_{s} / \rho_{b}\right)$. This means that the slip velocity is the decisive parameter of the erosion process for coal particles of the same type and diameter.

\section{Experimental Verification}

In order to verify the erosion formula in the equation (5), the tests of analysis of mass loss of different coal (table 2) for different mass rate flow of inert material and different collision velocity was carried out. The research was conducted on a test stand facilitating the modelling of real combustion conditions in CFB particularly in the middle and upper zone of the commercial CFB plants [10].

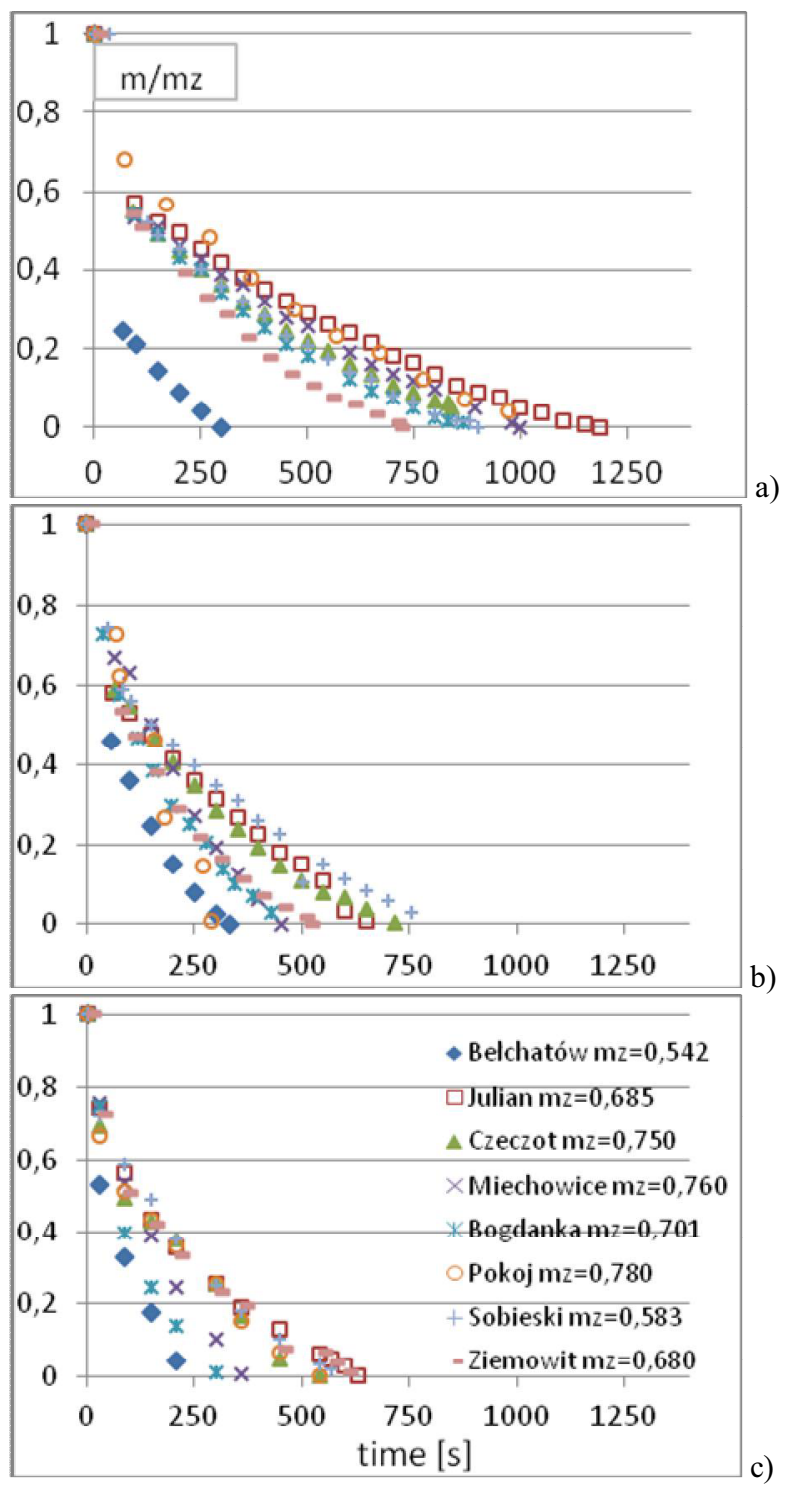

Fig.1. Relative mass loss of coal particles $(\mathrm{m} / \mathrm{mz})$ burning in air atmosphere a) and in flow of inert material for $\mathrm{Gs}=2.5 \mathrm{~b}$ ) and $\mathrm{Gs}=5.0 \mathrm{c}$ ).

The velocity of solid material in the core of the diluted zone is close to $u_{p} \sim 4 \mathrm{~m} / \mathrm{s}$. In the test, a manually 
prepared coal particle of $10 \mathrm{~mm}$ of chosen type was used. Details of the experiment and design of the test stand were described in [11]. The combustor chamber with measurements $80 \times 100 \times 120 \mathrm{~mm}$ was powered by $4 \mathrm{~kW}$ electric heaters and a temperature inside the combustor was $850 \mathrm{C}$. In the area of the burning coal, gravitationally accelerated quartz sand was entered. The particle size diameter of the solid material was typical for the commercial fluidized bed (Fig.2 "medium"). Figure1 presents the registered relative mass loss of coal of different types obtained during combustion, firstly in air atmosphere without interaction of inert material and then in conditions modelling combustion process in a fast FB. The mass rate flow of solid material was in turn: Gs $=0$; $2.5 ; 5.0 \mathrm{~kg} / \mathrm{m}^{2} \mathrm{~s}$. The results of proximate analysis were presented in Table 2. The range of mass rate flow was taken on the basis of the measurement of concentration in commercial boilers [10]. The registered mass loss of coal particles presented in Fig. 1 unequivocally indicates that the flow of inert material strongly accelerates the mass loss in relation to the registered in air atmosphere. The average rate of mass loss for the individual char of tested hard coals (after combustion of volatile matter) was within a range of $\mathrm{Gs}=0$ from $3.8 \times 10^{-7}$ (Julian mine) to $5.8 \times 10^{-7} \mathrm{~kg} / \mathrm{s}$ (Ziemowit mine). In the flow of inert material this range was clearly higher for $\mathrm{Gs}=2.5$ from $5.4 \times 10^{-7}$ (Sobieski mine) to $12.5 \times 10^{-7} \mathrm{~kg} / \mathrm{s}$ (Miechowice mine) and for $\mathrm{Gs}=5.0$ from $6.8 \times 10^{-7}$ (Ziemowit mine) to $15.2 \times 10^{-7} \mathrm{~kg} / \mathrm{s}$ (Miechowice mine). Thus, putting coal particles in the area of flow of inert material increased the rate of mass loss for $\mathrm{Gs}=2.5$ average $74 \%$ and for $\mathrm{Gs}=5.0107 \%$ in the relation to values registered for $\mathrm{Gs}=0$. However, the following questions are still valid: Which of the following factors: erosion, parameters of coal or hydrodynamic conditions around the particle has the biggest effect in the accelerated mass loss observed? What is the contribution of the first term of the equation (2), chemical reaction and the second term erosion to the total mass loss of fuel coal? How does the particle size distribution and collision velocity affect the erosion intensity? In order to estimate the attrition rate constant $k_{a}$ in equation (5), the determination of slip velocity $U_{g}$ between the burning coal particle and the solid material is necessary. During the experiment, a single coal particle was still placed inside the combustion chamber on the handle of a tensometric branch scale. The collision velocity may change as a result of change in the mean particle diameter used in the inert material. In order to estimate the slip velocity, it is sufficient to solve the easy set of equations describing the free drop of spherical particle in the viscid medium. The model results of calculation for particles of different diameters are presented in Table.3. In the experiment the inert material with different particle size distribution is presented in Fig.2 and the characteristic parameters shown in Table 4 were used.

This time the tests were carried out for two different coal types: from Sobieski mine (type 31.2) and from Miechowice mine (type 32.1). These coals characterised the biggest mass loss difference measured during the combustion in flow of inert material. The experiment was conducted for different mass flow rates respectively for Sobieski mine $G s \sim 4.0 ; 7.0$ and $15 \mathrm{~kg} / \mathrm{m}^{2} \mathrm{~s}$ and for Miechowice mine $G s \sim 1.5 ; 4.0$ and $6.5 \mathrm{~kg} / \mathrm{m}^{2} \mathrm{~s}$. In Fig. 3 a-f, the obtained results were presented.

Table 2. Results of proximate analyses of tested coals.

\begin{tabular}{|c|c|c|c|c|c|}
\hline \multirow{2}{*}{ Mine } & \multicolumn{5}{|c|}{ Proximate analyses } \\
\cline { 2 - 6 } & $\mathbf{V}$ & $\mathbf{W}$ & $\mathbf{A}$ & $\mathbf{F C}$ & $\mathbf{Q}$ \\
\cline { 2 - 6 } & $\%$ & $\%$ & $\%$ & $\%$ & $\mathrm{~kJ} / \mathrm{kg}$ \\
\hline $\begin{array}{c}\text { Belchatow } \\
\text { (lignite) }\end{array}$ & 42.5 & 14.5 & 18.5 & 24.5 & 18460 \\
\hline $\begin{array}{c}\text { Julian } \\
\text { (hard) }\end{array}$ & 37.5 & 7.6 & 5.9 & 49.0 & 29026 \\
\hline $\begin{array}{c}\text { Ziemowit } \\
\text { (hard) }\end{array}$ & 26.9 & 7.6 & 20.7 & 44.8 & 21179 \\
\hline $\begin{array}{c}\text { Sobieski } \\
\text { (hard) }\end{array}$ & 27.9 & 12.4 & 16.7 & 43.0 & 21558 \\
\hline $\begin{array}{c}\text { Czeczot } \\
\text { (hard) }\end{array}$ & 29.3 & 9.5 & 14.6 & 46.6 & 20300 \\
\hline $\begin{array}{c}\text { Miechowice } \\
\text { (hard) }\end{array}$ & 30.2 & 6.7 & 12.0 & 51.1 & 23000 \\
\hline $\begin{array}{c}\text { Bogdanka } \\
\text { (hard) }\end{array}$ & 27.8 & 2.9 & 25.4 & 43.9 & 22542 \\
\hline $\begin{array}{c}\text { Pokoj } \\
\text { (hard) }\end{array}$ & 31.5 & 1.9 & 2.7 & 63.9 & 31500 \\
\hline
\end{tabular}

Table 3. Results of numerical simulations of collision velocity.

\begin{tabular}{|c|l|l|}
\hline $\begin{array}{l}\text { Particle } \\
\text { diameter } \\
{[\mu \mathrm{m}]}\end{array}$ & $\begin{array}{l}\text { Velocity } \\
{[\mathrm{m} / \mathrm{s}]}\end{array}$ & $\boldsymbol{R e}$ \\
\hline 500 & 3.18 & 6.7 \\
\hline 400 & 2.5 & 5.3 \\
\hline 300 & 1.77 & 3.7 \\
\hline 200 & 1.08 & 2.3 \\
\hline 100 & 0.31 & 0.7 \\
\hline
\end{tabular}

On the basis of registered mass loss of coal particles from Sobieski mine, it may be noted that in the case of all mass rate flow inert material the time differences for fine medium and coarse particle size distribution are similar and do not exceed 100s. In the phase of combustion of volatile matter the mass loss is almost the same. Only differences in the phase of char combustion are observed. The smallest effect on the erosion mass loss was noted for combustion in the flow of coarse inert material, for which the equivalent Sauter diameter was $D a=485 \mu \mathrm{m}$. While the mass loss for medium and fine inert material was almost the same in the whole tested range of Gs, only in the case of the biggest mass flow rate $\left(15 \mathrm{~kg} / \mathrm{m}^{2} \mathrm{~s}\right)$ in the last stage of combustion was there a slightly bigger effect for fine material registered. A similar course of the phenomenon was observed for Miechowice coal. The influence of the particle size 
diameter in the analyzed range is close and the different result observed is most likely from the impurity of the coal prepared. In the case of the low mass rate flow Gs $=1.5 \mathrm{~kg} / \mathrm{m}^{2} \mathrm{~s}$, the overall time of mass loss registered for coarse inert material was very close to that obtained during the test on medium material.

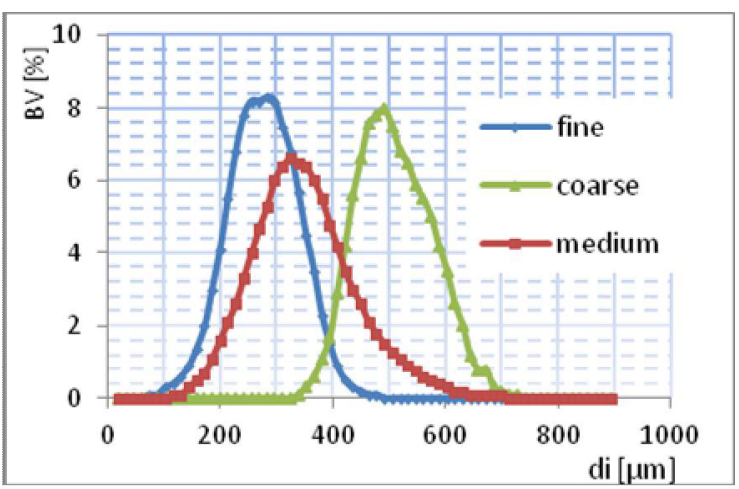

Fig.2. Particle size distribution of inert material used during the experiment.

Table 4. Parameters of used in experiment inert material.

\begin{tabular}{|l|l|l|l|}
\hline $\begin{array}{l}\text { Parametersof inert } \\
\text { material }[\mu \mathrm{m}]\end{array}$ & fine & medium & coarse \\
\hline $\begin{array}{l}\text { Dn- } \\
\text { arithmetical diameter }\end{array}$ & 127 & 169 & 49,1 \\
\hline $\begin{array}{l}D s- \\
\text { surface diameter }\end{array}$ & 165 & 219 & 126 \\
\hline $\begin{array}{l}D v- \\
\text { volume diameter }\end{array}$ & 247 & 319 & 485 \\
\hline $\begin{array}{l}\text { Da- } \\
\text { Sauter diameter }\end{array}$ & 74,8 & 88,2 & 22,1 \\
\hline $\begin{array}{l}\text { Dgeo- } \\
\text { geometrical diameter }\end{array}$ & 117 & 186 & 16,3 \\
\hline Dmed & 9,9 & 9,9 & 9,9 \\
\hline Dmod & \multicolumn{1}{|l}{} \\
\hline
\end{tabular}
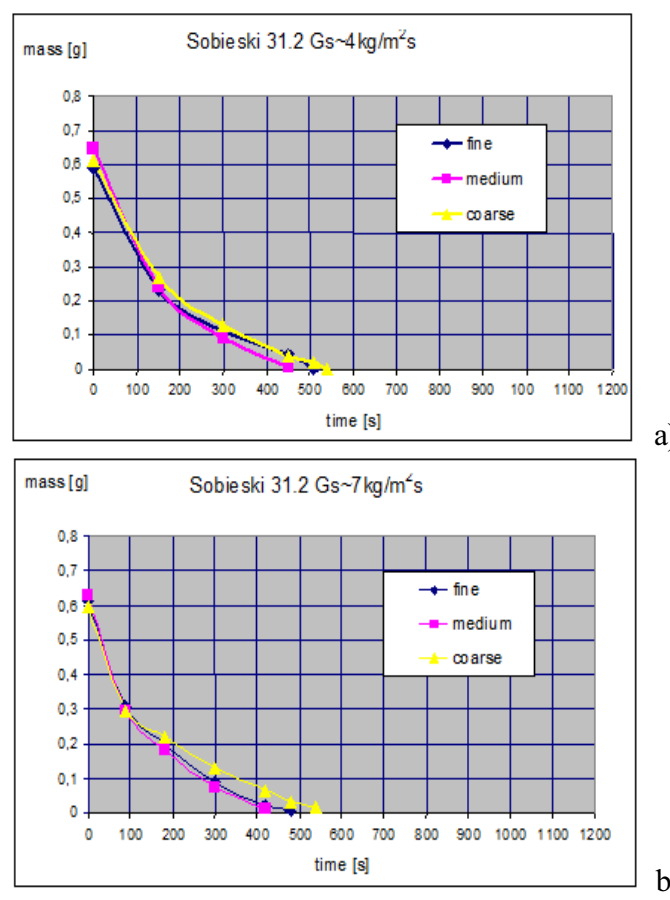

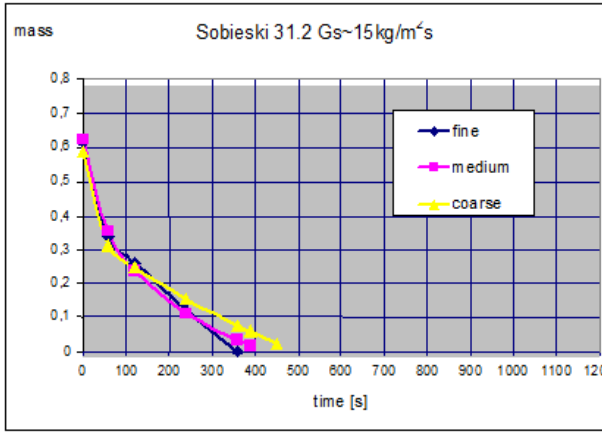

c)

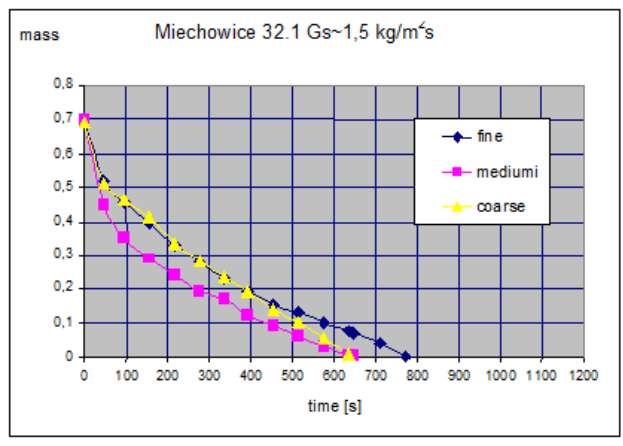

d)

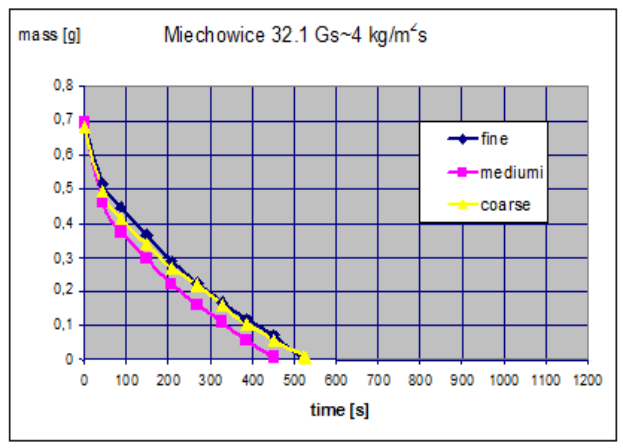

e)

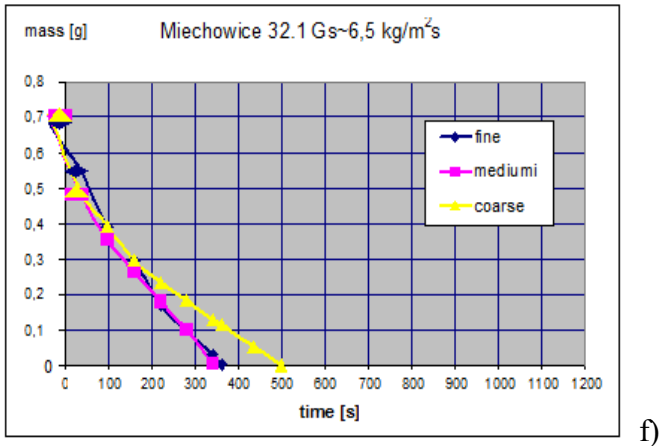

Fig.3. Mass loss of coal particles: a, b, c from Sobieski and $\mathrm{d}, \mathrm{e}, \mathrm{f}$ from Miechowice mine during the combustion in different flow of solid and different particle size distribution.

With the increasing mass rate flow, the difference of overall time of mass loss for fine and medium material increases and for $G s=6.5 \mathrm{~kg} / \mathrm{m}^{2} \mathrm{~s}$ is about $150 \mathrm{~s}$ in favour of medium material.

While exactly the opposite trend may be seen for fine inert material, which for the lowest mass flow rate distinguishes the smallest influence the erosion mass loss (time difference $\Delta t_{c}=120 \mathrm{~s}$ ), and with an increase to $G s=6.5$ was almost the same as the biggest mass loss observed for the medium solid material. Thus, on the basis of the tests carried out, it may be stated that the particle size distribution in the chosen range is not important for the generation of erosion mass loss. The 
overall time difference of mass loss for all cases did not exceed $15 \%$ despite the Sauter diameter being twice bigger between the fine and coarse material. The one trend noted (in five out of six considered cases) is the smallest erosion mass loss caused by the fine solid material with the highest slip velocity between the char particles.

\section{Conclusions}

The research conducted confirmed that the combustion of coal fuel in the flow of inert material characterises much greater mass loss. The loss is caused as a result of oxidation reaction and the erosion process running simultaneously. The erosion process causes abrasion (attrition) of the ash layer forming during combustion and the external weakened char surface. The rate of mass loss for the parameters taken in the tests presented that match the conditions in the middle and upper zone of CFB boilers may be even more than $100 \%$ in relation to combustion without the influence of inert material. The results obtained in the second part of the research on materials with three different particle size distributions with the Sauter diameter were respectively: $247 ; 319 ; 485 \mu \mathrm{m}$ which indicate that the size of solid particles and slip velocity between inert material and burning coal particle has no important meaning. It suggests that the proposed equation of attrition rate char in subject-related literature either incorrectly describes the real mechanism of mass loss or the contribution of erosion process in mass loss is negligible. The difference of the mass loss rate for both coal types and three particle size distributions applied do not exceed $15 \%$ and are of a random nature. It may be stated that the increasing mass loss rate observed in all the analyzed particle size distributions is due to the same factor. This is most likely the intensification of the diffusion of reactants and products in the reaction area on the burning coal particle surface. Hitting the coal surface and flowing in the area of burning coal inert material notably improves mass exchange. The increase of their size and slip velocity have a small influence on the process tested. The primary role of the erosion process is the attrition of ash forming on the surface reaction.

\section{Nomenclature}

$A \quad$ - external surface area of char, $\mathrm{m}^{2}$

$c_{g} \quad$ - oxygen concentration in partial pressure, $\mathrm{kPa}$

$d_{a v} \quad$ - average carbon particle diameter, $\mathrm{m}$

$d_{c} \quad$ - average diameter of char particle, $\mathrm{m}$

$D_{g} \quad$ - molecular diffusivity of oxygen, $\mathrm{m}^{2} / \mathrm{s}$

$E \quad$ - activation energy, $\mathrm{kJ} / \mathrm{kmol}$

$G_{s} \quad$ - circulation rate in fast bed, $\mathrm{kg} / \mathrm{m}^{2} \mathrm{~s}$

$h_{m} \quad$ - mass transfer coefficient, $\mathrm{kg} / \mathrm{m}^{2} \mathrm{kPa} \mathrm{s}$

$k_{a} \quad$ - attrition rate constant

$k_{c} \quad$ - kinetic rate constant, $\mathrm{kg} / \mathrm{m}^{2} \mathrm{~s} \mathrm{~Pa}$

$k_{o} \quad$ - frequency factor, $\mathrm{kg} / \mathrm{m}^{2} \mathrm{~s} \mathrm{~Pa}$

$m$ - mass of coal particle, $\mathrm{kg}$ $m_{z} \quad$ - initial mass of coal particle, $\mathrm{kg}$

$q \quad$ - specific burning rate, $\mathrm{kg} / \mathrm{m}^{2} \mathrm{~s}$

$R$ - gas constant, $8.314 \mathrm{kPa} \mathrm{m}^{3} / \mathrm{kmol} \mathrm{K}^{2}$

Sh - Sherwood number

$T_{s} \quad$ - temperature of the surface of the char, $\mathrm{K}$

$T_{m} \quad$ - mean temperature of the diffusion layer around the char particle, $\mathrm{K}$

$U_{c} \quad$ - char velocity, $\mathrm{m} / \mathrm{s}$

$U_{g} \quad$ - superficial gas velocity, $\mathrm{m} / \mathrm{s}$

$W_{c} \quad$ - overall mass loss, $\mathrm{kg}$

$\phi \quad$ - mechanism factor

$\rho_{b} \quad$ - bulk density of the fast bed, $\mathrm{kg} / \mathrm{m}^{3}$

\section{References}

1. P.K. Halder, Ph.D. Thesis, Technical University of Nova Scotia, (1989)

2. P. Basu, Combustion and gasification in fluidized bed. Taylor \& Francis Group, (2006)

3. P. Basu, Chem. Eng. Sci. 54, 5547 (1999)

4. R. Chirone, L. Massimilla, P. Salatino, Prog. Energy Combust. Sci. 17, 297 (1991)

5. Z. Bis, Kotly fluidalne, teoria $i$ praktyka. Czestochowa University of Technology, (2010)

6. O. Levenspiel, Chemical reaction engineering (2nd Ed.) New Delhi: Wiley Eastern Ltd. 368 (1984)

7. Basu P., Fraser S.A.: Circulating fluidized bed boilers - design and operations, 95 (1991)

8. I.B. Ross, Ph.D. Dissertation, University of Cambridge, U.K., (1979)

9. P.K. Halder, P. Basu, Chem. Eng. Sci., 47, 527 (1992)

10. R. Sekret, Warunki cieplno-przeptywowe $i$ emisje zanieczyszczeń $w$ kotłach $z$ cyrkulacyjna warstwa fluidalna dużej mocy, Silesian University of Technology, 1694 Gliwice (2005)

11. P. Pelka, Combust. Flame 156, 1604 (2009) 